\title{
Long-term maintenance of pediatric asthma: focus on budesonide/formoterol inhalation aerosol
}

This article was published in the following Dove Press journal:

Therapeutics and Clinical Risk Management

7 February 2010

Number of times this article has been viewed

Peter N Huynh'

Lyne G Scott ${ }^{\prime}$

Kenny YC Kwong ${ }^{2}$

'Division of Allergy-Immunology, Department of Pediatrics, Los Angeles County, University of Southern California Medical Center, Los Angeles, CA, USA; '2Division of Allergy-Immunology, Department of Pediatrics, Harbor-UCLA Medical Center, Torrance, CA, USA
Correspondence: Kenny Yat-Choi Kwong Division of Allergy-Immunology, Department of Pediatrics, Harbor-UCLA Medical Center, 1000 West Carson Street Box 49I, N-25, USA

Email kkwongusc@yahoo.com

\begin{abstract}
Current national and international asthma guidelines recommend treatment of children with asthma towards achieving and maintaining asthma control. These guidelines provide more stringent recommendations to increase therapy for patients with uncontrolled asthma in order to reduce asthma-related morbidity and mortality. Newer combination agents such as budesonide and formoterol have been shown to be safe and effective in treatment of asthma in children. Use of long-term controller agents like this in combination with improved compliance and treatment of co-morbid conditions have been successful in this endeavor. This review discusses control of pediatric asthma with focus on the use of budesonide in combination with formoterol.
\end{abstract}

Keywords: asthma, control, children, budesonide, formoterol, long-term

\section{Introduction}

National and international asthma treatment guidelines have recently focused on control of asthma. These guidelines provide more stringent recommendations to increase therapy for patients with uncontrolled asthma in order to reduce asthma related morbidity and mortality. Further, they recommend different combinations of controllers for long term treatment of persistent asthma including addition of long-acting $\beta_{2}$-agonists (LABA) to inhaled corticosteroid (ICS) therapy. ${ }^{1,2}$ This review discusses control of pediatric asthma with focus on the use of budesonide in combination with formoterol.

\section{Diagnosis of asthma in children}

Before long term controller medication can be initiated, the diagnosis of asthma must be made. Many studies show that asthma is under diagnosed particularly in children. ${ }^{3-5}$ Asthma is a chronic inflammatory disease of the airways characterized by episodic and reversible airflow obstruction. A clinical diagnosis of asthma is often prompted by symptoms of cough, shortness of breath, chest tightness, or wheezing. Spirometry is the recommended method of objectively measuring airflow obstruction and reversibility. Diagnosis of asthma is supported by reversible airflow obstruction as measured by forced expiratory volume at one second $\left(\mathrm{FEV}_{1}\right)$ by more than $12 \%$ after bronchodilator therapy. ${ }^{6,7}$ There is no single diagnostic test for asthma, but careful review of symptoms along with physical examination and objective measurements of lung function can guide the clinician toward diagnosis. A detailed discussion on the differential diagnosis of asthma is beyond the scope of this review. 
The diagnosis of asthma in younger children often presents a challenge for clinicians because episodic wheezing and cough are also common in children who do not have asthma. More than $50 \%$ of children in the United States and the United Kingdom wheeze in their first year of life. ${ }^{8}$ The diagnosis of asthma is further complicated by the difficulty in obtaining objective measurements of lung function in children aged less than five years, the lack of definitive biomarkers, and the difficulty in discerning among the different asthma phenotypes. ${ }^{9-11}$

Castro-Rodriguez and colleagues developed the Asthma Predictive Index (API), ${ }^{12}$ a practical tool that helps clinicians identify children who are more likely to have asthma. This simple clinical index based on the presence of wheeze before the age of three, and the presence of one major risk factor (parental history of asthma or a personal history of atopic dermatitis) or two of three minor risk factors (allergic rhinitis, wheezing apart from colds, and eosinophilia), has been shown to predict the presence of asthma in later childhood. The API has a positive predictive value of $76 \%$ and a negative predictive value of $95 \%$ (Figure 1).

\section{Asthma control in children}

Currently most asthma guidelines measure asthma control using two domains consisting of 1) present asthma symptoms and lung function and 2) history of past asthma exacerbations. ${ }^{1,2}$ In the 2007 National Asthma Education Prevention Program Expert Review Panel 3 (NAEPP ERP 3) guidelines, assessment of a combination of current asthma symptoms (such as frequency of day and night symptoms), lung function, and asthma survey instruments such as the Asthma Control Test (ACT) are used to measure patient's current impairment due to asthma. The number of prior asthma exacerbations requiring systemic steroid rescue is used to measure patient's risk (Figure 2). Impairment and risk are then used to determine the level of patient's asthma control. Long term asthma control reduces asthma associated impairment and is believed to result in reduced risk of exacerbations. ${ }^{13}$ We previously demonstrated that inner city asthmatic children who maintained a high degree of asthma control over the period of a year had a significantly lower risk of asthma exacerbations and emergency department visits/hospitalizations compared to similar children who had poor asthma control (Figure 3). ${ }^{14}$

Previous asthma guidelines recommended classification of asthma severity upon initial assessment prior to controller treatment. This was an attempt to determine the baseline "controller naïve" asthma severity in patients and the level of controller therapy required. ${ }^{1,2}$ A recent update of those guidelines still recommends baseline classification of severity, but only as an initial starting reference point. Many patients initially seen by providers are not controller naïve and recent studies have demonstrated that asthma disease activity may vary over time and deviate significantly from the initial baseline classification. Patients initially classified with intermittent asthma may experience severe exacerbations at distal time points. ${ }^{15,16}$

\begin{tabular}{|c|c|}
\hline \multicolumn{2}{|c|}{ Four episodes of wheezing in one year } \\
\hline Major criteria & Minor criteria \\
\hline Parent with physician-diagnosed asthma & Wheezing apart from colds \\
\hline Physician-diagnosed eczema & Physician-diagnosed allergic rhinitis \\
\hline & Eosinophilia (>4\%) \\
\hline
\end{tabular}

Figure I Asthma Predictive Index. History of early wheezing in a child with at least one major criteria or two minor criteria had a positive predictive index of $76 \%$ in children. Copyright () 2008, American Thoracic Society. Adapted from Castro-Rodriguez JA, Holberg CJ, Wright AL, Martinez FD. A clinical index to define risk of asthma in young children with recurrent wheezing. Am J Respir Crit Care Med. 2000; 162:1403-1406. 


\begin{tabular}{|c|c|c|c|c|}
\hline & & \multicolumn{3}{|c|}{$\begin{array}{l}\text { Classification of asthma control } \\
\text { (5-11 years of age) }\end{array}$} \\
\hline & & Well controlled & $\begin{array}{l}\text { Not well } \\
\text { controlled }\end{array}$ & $\begin{array}{c}\text { Very poorly } \\
\text { controlled }\end{array}$ \\
\hline \multirow[t]{6}{*}{ Impairment } & Symptoms & $\leq 2$ days/week & $>2$ days/week & Daily \\
\hline & $\begin{array}{c}\text { Night-time } \\
\text { awakenings }\end{array}$ & $\leq 1 x /$ month & $>2 x /$ month & $>2 x /$ week \\
\hline & $\begin{array}{l}\text { Interference with } \\
\text { normal activity }\end{array}$ & None & Some limitation & Extremely limited \\
\hline & $\begin{array}{l}\text { SABA use for } \\
\text { symptom control }\end{array}$ & $\leq 2$ days/week & $>2$ days/week & Several times/day \\
\hline & $\begin{array}{l}\text { Lung function: } \\
-F E V_{1} \text { or peak } \\
\text { flow }\end{array}$ & $\begin{array}{c}>80 \% \\
\text { predicted/personal } \\
\text { best }\end{array}$ & $\begin{array}{c}60 \%-80 \% \\
\text { predicted/personal } \\
\text { best }\end{array}$ & $\begin{array}{c}<60 \% \\
\text { predicted/personal } \\
\text { best }\end{array}$ \\
\hline & $-\mathrm{FEV}_{1} / \mathrm{FVC}$ & $>80 \%$ & $75 \%-80 \%$ & $<75 \%$ \\
\hline Risk & $\begin{array}{l}\text { Exacerbations } \\
\text { requiring oral } \\
\text { systemic } \\
\text { corticosteroids }\end{array}$ & 0-1/year & \multicolumn{2}{|c|}{$\geq 2 /$ year } \\
\hline
\end{tabular}

Figure 2 Assessing asthma control in children aged 5-II years. Refer to NAEPP guidelines for other age groups. Adapted from National Asthma Education and Prevention Program. Guidelines for the Diagnosis and Management of Asthma: Expert Panel Report 3. Bethesda, MD: National Institutes of Health, National Heart, Lung and Blood Institute; 2007.

Abbreviations: $\mathrm{FEV}_{1}$, forced expiratory volume in one second; FVC, forced vital capacity; SABA, short-acting $\beta_{2}$-agonists.

For instance, it is well described that young children may have relatively mild asthma symptoms (impairment) throughout the year, but may have severe exacerbations during periods of viral infections (risk). ${ }^{17,18}$ Congruent with these observations, guidelines stress that ongoing monitoring of disease activity is essential to maintaining asthma control wherein asthma control is the measurement used during real time assessment of asthmatics at each provider encounter. Dynamic pharmacologic therapy using a stepwise approach is recommended with "step up" of controller agents when control is poor and "step down" of medications when control is maintained for extended periods of time (Figure 4).

\section{Compliance and treatment of co-morbid conditions}

Compliance and treatment of co-morbid conditions play major roles in achievement of asthma control in children. Asthma is a chronic disease and long term treatment is imperative to reduce risk of morbidity and mortality. Consistent with findings of other investigators, we have shown that compliance is a major independent variable that contributes towards maintaining asthma control in inner city asthmatic children once initial disease control was achieved. ${ }^{19,20}$ Long-term compliance is unfortunately suboptimal in many asthmatic children, which contributes to poor asthma control in these patients. Reasons for this include poor patient understanding of the disease, complexity of treatment, access to care and medications, and socioeconomic factors. ${ }^{21,22}$

Control of co-morbid conditions including allergic rhinitis, sinusitis, and gastroesophageal reflux disease (GERD) are important in achieving asthma control in children. This often allows asthma control using lower doses of controller agents, reducing risk of side effects. Pathology of the upper airway is believed to adversely impact the lower airways of asthmatics via mechanisms that are not completely understood. However, neuronal and inflammatory pathways have been implicated. ${ }^{23,24}$ Treatment of the upper airway with intranasal steroids, antihistamines, and leukotriene receptor antagonists (LTRA) have been shown to improve asthma control. ${ }^{25-27}$ Control of GERD with proton pump inhibitors, $\mathrm{H}_{2}$ blockers and surgery has also been shown to improve asthma symptoms and reduce doses of controller agents required. ${ }^{28,29}$

\section{Controller agents recommended for long-term asthma control in children \\ Inhaled corticosteroids}

Inhaled corticosteroids (ICS) remain the cornerstone of asthma treatment for children of all ages. ${ }^{1,2}$ They are the most potent and effective anti-inflammatory medication currently available. 


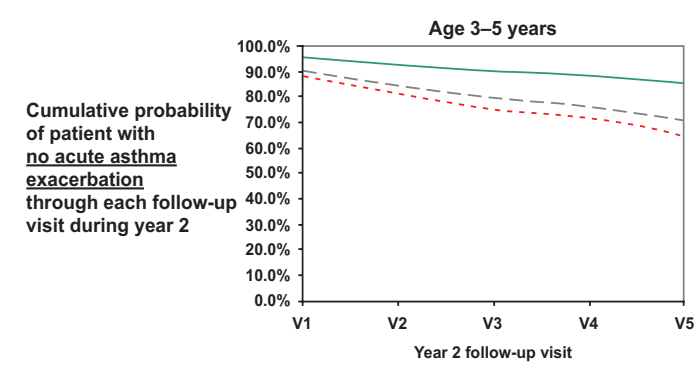

Asthma Control during Year One (\% follow-up visit)

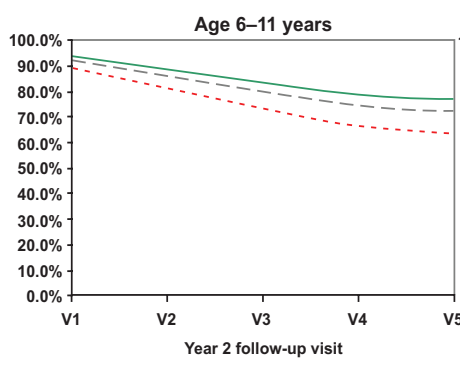

Well Controlled $(\geq 80 \%)$

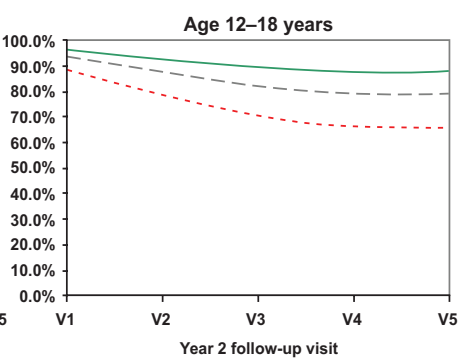

Moderate Control (50-79.9\%)

Difficult to Control (<50\%)

Figure 3 Degree of asthma control during year I was associated with probability of asthma exacerbation during year 2 in inner city children with asthma living in Los Angeles. Degree of asthma control was defined as the percentage of clinic visits during year I when asthma was rated as controlled based upon NAEPP ERP 2 asthma guidelines. Copyright () 2008, Elsevier. Adapted from Kwong KY, Morphew T, Scott L, Guterman J, Jones CA. Asthma control and future asthma-related morbidity in inner-city asthmatic children. Ann Allergy Asthma Immunol. 2008; 10 I (2): 144-I52.

Corticosteroids block late-phase reaction to allergens, reduce airway hyperresponsiveness, and inhibit inflammatory cell migration and activation. ${ }^{30-32}$ ICS reduce asthma symptoms, improve quality of live, reduce frequency and severity of exacerbations, and reduce asthma mortality. ${ }^{33-35}$ The potential but small risk of adverse effects from ICS is well balanced by their efficacy. Local adverse effects include oropharyngeal candidiasis and dysphonia. Systemic adverse effects of longterm treatment with high doses of ICS include easy bruising, ${ }^{36}$ adrenal suppression, ${ }^{37,38}$ and decreased bone mineral density. ${ }^{39}$ The risk of systemic adverse effects depends upon its dose and potency. Low and medium doses of ICS appear to have no serious adverse effects on bone mineral density in children. ${ }^{40}$ In addition, low and medium dose ICS have no significant effects on the incidence of subcapsular cataracts or glaucoma. ${ }^{41}$ Perhaps the more significant adverse effect of ICS is growth velocity reduction in children. The available cumulative data suggest that even low-dose ICS have the potential for decreasing growth velocity, although the effects are small. ${ }^{42,43}$ Despite a small reduction in growth velocity, studies of early intervention with low- or medium-dose ICS showed significantly improved asthma outcomes. ${ }^{33,44}$

The efficacy and tolerability of the ICS, budesonide, is well established in the treatment of pediatric asthma. ${ }^{45,46}$ One of the largest and longest studies demonstrating the benefit of ICS in pediatric patients with asthma is the Childhood Asthma Management Program (CAMP). ${ }^{47}$ 1,041 children aged from 5 to 12 years with mild-to-moderate asthma were randomly assigned to receive either 1) budesonide, 2) nedocromil, or 3) placebo and were followed for four to six years (mean 4.3 years) . Children given budesonide experienced fewer hospitalizations and urgent care visits, decreased symptoms, decreased need for albuterol rescue therapy, and fewer episodes of acute asthma requiring oral prednisone.
However, neither budesonide nor nedocromil was better than placebo in terms of improving lung function in the long term. These findings suggest that continuous, longterm ICS treatment of children did not prevent deficits in lung function and did not alter the rate of progression of asthma. Side effects of budesonide included small, transient reduction in growth velocity. The mean increase in height in the budesonide group was $1.1 \mathrm{~cm}$ less than the mean increase in the placebo group. The difference between the budesonide and placebo groups in the rate of growth was evident primarily within the first year of treatment.

The CAMP investigators speculated that ICS did not affect the natural course of asthma because treatment did not begin early enough. The Prevention in Early Asthma in Kids study (PEAK) attempted to address this issue. The PEAK study was a multicenter, double-blind, randomized, placebo-controlled trial that investigated whether daily ICS could prevent the development of chronic asthma. 285 children aged two or three years with a positive asthma predictive index were randomized to receive either fluticasone propionate $(88 \mu \mathrm{g}$ twice daily) or masked placebo for two years, followed by a one-year period of observation without study medications. ${ }^{42}$ During the treatment period, the children who received ICS had a greater proportion of episode-free days, a lower rate of asthma exacerbations, and decreased supplementary use of controller medications. However, during the observation period, no significant differences were seen between the two groups in the proportion of episode-free days, the number of exacerbations, or lung function. Therefore, in preschool children at high risk for asthma, two years of ICS therapy did not change the development of asthma symptoms or lung function during the third, treatment-free year. Congruent with findings from the CAMP study, the children who received ICS had a mean increase in height $1.1 \mathrm{~cm}$ less than the mean 


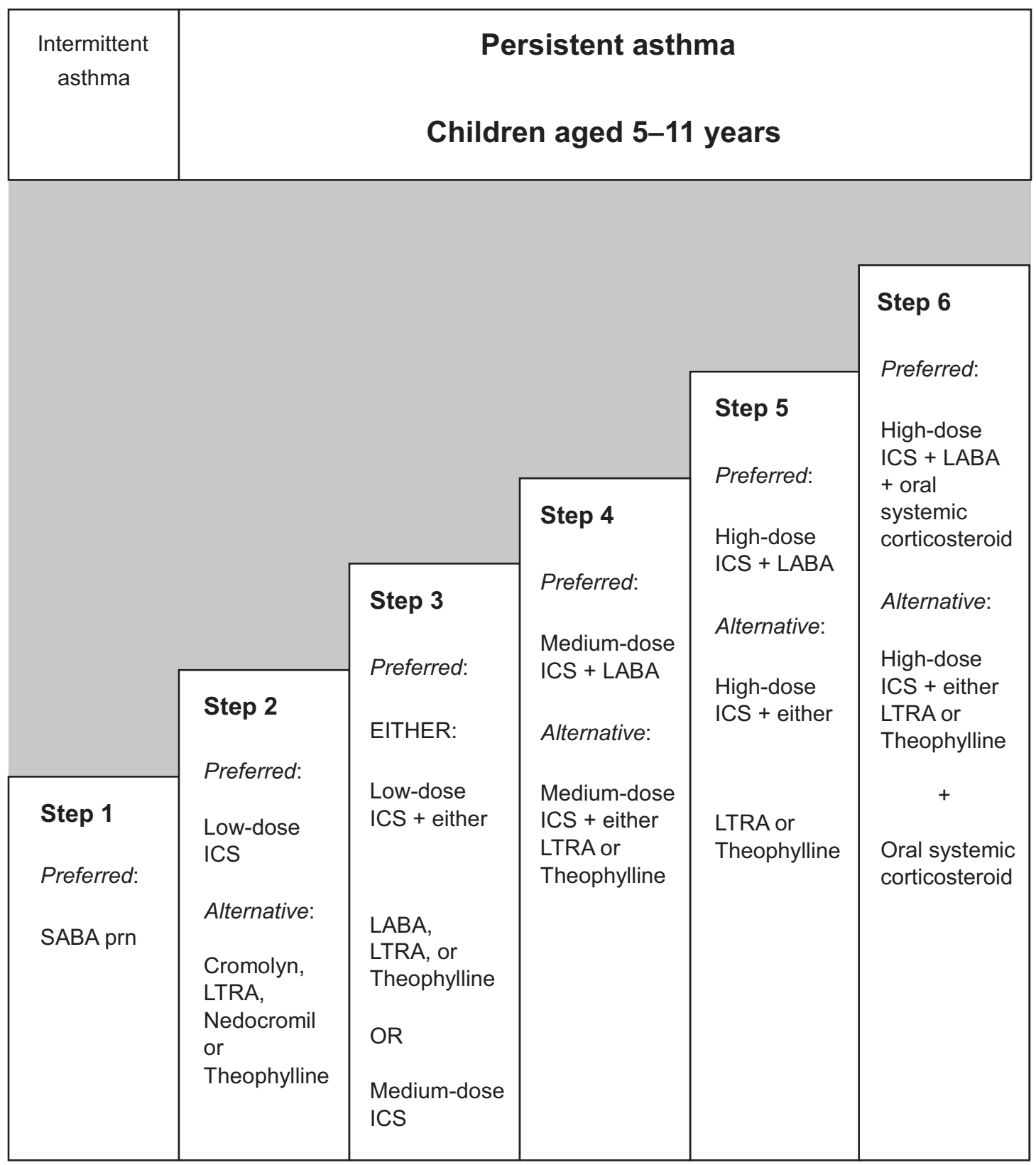

Figure 4 Stepwise Approach for managing asthma in children aged 5-II years. Refer to NAEPP guidelines for other age groups. Adapted from National Asthma Education and Prevention Program. Guidelines for the Diagnosis and Management of Asthma: Expert Panel Report 3. Bethesda, MD: National Institutes of Health, National Heart, Lung and Blood Institute; 2007.

Abbreviations: ICS, inhaled corticosteroids; LABA, long-acting $\beta_{2}$-agonists; LTRA, leukotriene receptor agonists; SABA, short-acting $\beta_{2}$-agonists.

increase in the placebo group at 24 months. However, by the end of the trial, the height increase was only $0.7 \mathrm{~cm}$ less.

The START study evaluated the safety and tolerability of long-term treatment of both children and adults who have mild persistent asthma. ${ }^{48} 17.8 \%$ and $27.8 \%$ of the patients in this study were aged $11-17$ and 5-10 years, respectively. In the first three years of the START study, patients with mild persistent asthma who received low-dose daily budesonide had a reduction in their risk of a first severe asthma-related event by $44 \%$ compared to similar patients given placebo. Thus budesonide significantly reduced the overall risk of experiencing a severe asthma-related event in these pediatric patients. Similar to the CAMP study, children given budesonide compared to those receiving placebo experienced small reductions in growth velocity. However, low-dose daily budesonide was associated with significantly less effect on growth than with previously reported studies with high-dose budesonide. 
A long-term placebo-controlled study by Agertoft and colleagues involving 211 children who received long-term treatment with budesonide (mean duration 9.2 years) reported no adverse effects on final height. ${ }^{49}$ The mean daily dose of budesonide was $412 \mu \mathrm{g}$ (range, 110 to 877 ) and the mean cumulative dose of budesonide was $1.35 \mathrm{~g}$ (range, 0.41 to 3.99). Growth rates were significantly reduced during the first years of budesonide treatment; however, these changes in early growth rate were not significantly associated with reductions in predicted final adult height. Other studies using long-term treatment with ICS show similar catch-up growth after the initial period of administration. ${ }^{50-53}$

Taken together, these studies demonstrate that ICS significantly improve symptoms, reduce impairment, and reduce the likelihood of asthma-associated morbidity in children with asthma. The significant benefit of this agent is balanced with the risk of linear growth reduction especially during initial periods of use which may be caught up over time.

\section{Combination therapy in children}

NAEPP EPR 3 recommend combination therapy for the majority of children with moderate to persistent asthma. ${ }^{15}$ The most popular combinations are the use of ICS in combination with LABA and ICS in combination with LTRAs.

\section{Inhaled corticosteroids in combination with long-acting $\beta_{2}$-agonist}

Numerous studies have established that the addition of LABA to ICS in adults is more effective at controlling symptoms, improving lung function, and reducing asthma exacerbations than doubling the dose of ICS. In the Formoterol and Corticosteroids Establishing Therapy (FACET) study, Pauwels and colleagues reported that in adult patients with moderate asthma, the addition of formoterol to low or moderate doses of budesonide reduced the frequency of asthma exacerbations, improved symptoms, and lung function. ${ }^{54}$ In this double-blind parallel group study, 852 patients were randomly assigned to receive one of the following treatments for one year: 1) budesonide $100 \mu \mathrm{g}$ bid, 2) budesonide/ formoterol $100 \mu \mathrm{g} / 12 \mu \mathrm{g}$ bid, 3 ) budesonide $400 \mu \mathrm{g}$ bid, or 4) budesonide/formoterol $400 \mu \mathrm{g} / 12 \mu \mathrm{g}$ bid. A post-hoc analysis of the FACET study confirmed that the addition of formoterol to low-dose budesonide increases the probability of well controlled asthma compared to a substantial increase in the dose of ICS.

The OPTIMA trial was a double-blind, randomized, and parallel-group study designed to determine whether regular treatment with low doses of inhaled budesonide, with or without doses of inhaled formoterol, would reduce severe asthma exacerbations and improve asthma control. In one arm of the trial, patients aged 12 years and older who were already taking budesonide at baseline were randomized to receive: 1) budesonide $100 \mu \mathrm{g}$ bid, 2) budesonide/ formoterol $100 \mu \mathrm{g} / 4.5 \mu \mathrm{g}$ bid, 3) budesonide $200 \mu \mathrm{g}$ bid, or 4) budesonide/formoterol $200 \mu \mathrm{g} / 4.5 \mu \mathrm{g}$ bid. ${ }^{55}$ The addition of formoterol reduced the risk for severe asthma exacerbations and improved asthma control more effectively than doubling the dose of budesonide.

Numerous other studies and meta-analysis of adults and children aged 12 years and older have established that the combination of ICS/LABA is more effective at controlling symptoms, improving lung function, and reducing asthma exacerbations than doubling the dose of ICS. ${ }^{56-59}$ However, there have been only a few studies of the efficacy of ICS/LABAs in asthmatics less than 12 years old, and to the best of our knowledge, none in children aged less than five years.

Tal and colleagues evaluated the effect on lung function and tolerability of budesonide/formoterol in a single inhaler in children (mean age 11 years) with moderate to persistent asthma. ${ }^{60}$ This was a 12 -week, double-blind, parallel-group, multicenter trial that randomized 286 asthmatic children to either budesonide/formoterol $90 / 9 \mu \mathrm{g}$ bid or budesonide $200 \mu \mathrm{g}$ bid. Children who received combination budesonide/ formoterol had increased morning peak expiratory flow (PEF) relative to baseline compared to budesonide alone (7.22\% predicted normal versus $3.45 \%$ predicted normal, respectively). Evening PEF also increased significantly with budesonide/formoterol compared to budesonide alone (6.13\% predicted normal versus $2.73 \%$ predicted normal, respectively). Mean $\mathrm{FEV}_{1}$ and serial $\mathrm{FEV}_{1}$ measured over 12 hours increased significantly with budesonide/formoterol compared to budesonide alone. Combination budesonide/ formoterol in a single inhaler provided rapid improvements in PEF and $\mathrm{FEV}_{1}$ compared to inhaled budesonide alone. The two treatment groups were similar in their adverse event profile and rates of discontinuation.

In a similar study by Pohunek and colleagues, investigators compared the efficacy and safety of combination therapy with budesonide and formoterol versus budesonide alone in children ages 4 to 11 years. ${ }^{61}$ In a 12-week, double-blind study, 630 children were randomized to: 1) budesonide/formoterol 90/9 $\mu \mathrm{g}$ bid, 2) budesonide $200 \mu \mathrm{g}$ bid, and 3) budesonide $(90 \mu \mathrm{g})+$ formoterol $(9 \mu \mathrm{g})$ in separate inhalers. The budesonide/ formoterol combination significantly improved morning 
$\mathrm{PEF}$, evening $\mathrm{PEF}$, and $\mathrm{FEV}_{1}$ compared with budesonide alone. There was no significant difference between the budesonide/ formoterol and budesonide + formoterol in separate inhalers. The adverse event profiles were similar in all groups and there were no serious asthma-related adverse events in any treatment group. Combination budesonide/formoterol significantly improved lung function in children aged 4 to 11 years with asthma compared to budesonide alone.

These studies, although small, suggest that budesonide/ formoterol combination is a safe and effective treatment option for children with asthma.

Salmeterol and formoterol are highly selective, third generation LABAs that have been available for use since the early 1990s. Salmeterol and formoterol, however, differ in their pharmacological properties. One important difference is that the onset of action of formoterol is faster than that of salmeterol. ${ }^{62,63}$ A significantly greater improvement in $\mathrm{FEV}_{1}$ was noted within three minutes of dosing with formoterol than salmeterol and continued to have a more pronounced effect for the three hours following dosing. Formoterol produces bronchodilation as fast as the short-acting $\beta_{2}$-agonist salbutamol. ${ }^{64,65}$ In the Salmeterol Multicenter Asthma Research Trial, comparing daily treatment with salmeterol or placebo added to standard asthma therapy for adults resulted in an increased risk of asthma-related deaths in patients treated with salmeterol (13 deaths out of 13,176 patients treated with salmeterol versus three deaths out of 13,179 patients treated with placebo). ${ }^{66}$ In addition, increased numbers of severe asthma exacerbations were noted in the trials submitted to the US Food and Drug Administration (FDA) for formoterol approval. ${ }^{67}$ The association with severe asthma exacerbations and asthmarelated deaths has resulted in a black box warning label on all preparations containing LABAs. A single nucleotide (Arg-Arg versus Gly-Gly) substitution in the $\beta_{2}$-agonist receptor gene may be associated with worsening of asthma in this subset of patients taking salmeterol. ${ }^{68,69}$ It is worth noting that an increased risk of asthma-related deaths was not seen in the subset of patients reporting ICS use at baseline. Likewise, the evidence for increased risk of severe exacerbations from LABAs may stem from studies that compared monotherapy with LABAs versus monotherapy with ICS. ${ }^{70,71}$ Although it is still unclear whether salmeterol in combination with ICS still results in worsening of asthma in patients with the Arg-Arg genotype, a recent large retrospective study showed no such association. ${ }^{72}$ LABA must never be used as monotherapy and should be always used in combination with ICS.

\section{Inhaled corticosteroid in combination with leukotriene receptor antagonists}

Use of LTRAs as adjunctive therapy to ICS has not been studied well in children aged 5-11 years and has not been studied at all in children aged less than four years. The majority of studies have been done using adult subjects. LTRAs may be added when asthma is not controlled on ICS alone. Lofdahl and colleagues showed that addition of montelukast to beclomethasone significantly improved FEV $_{1}$ in asthmatics aged 15 years and older. ${ }^{73}$ Furthermore, addition of LTRA to ICS may be an effective and well tolerated alternative to doubling the dose of ICS in patients with uncontrolled asthma. In the COMPACT study, adult asthmatics with inadequately controlled asthma showed similar improvements in symptoms, exacerbations, symptomfree days, peripheral eosinophil counts, and asthma-specific quality of life when given a LTRA in addition to their current dose of ICS or had their ICS dose doubled. ${ }^{74}$ Finally addition of LTRAs to ICS may also allow reduction of ICS dose in asthmatics. ${ }^{75}$ In a double-blind, placebo-controlled study, 26 adult patients with stable asthma on ICS were randomized to montelukast or placebo for up to 12 weeks. Compared to placebo, montelukast allowed significant reduction in the ICS dose. LTRAs may be used as monotherapy in patients with mild asthma (step 2 in NAEPP ERP 3 and 2006 GINA) although ICS are often the preferred choice. ${ }^{1,2}$

Currently most asthma guidelines recommend addition of LABA versus LTRA to ICS as the preferred strategy in most age groups of children with asthma. While several studies have compared LABA versus LTRA addition to ICS in terms of efficacy, a detailed discussion is beyond the scope of this review, and may be found elsewhere. ${ }^{76-78}$

\section{New paradigm: combination therapy as maintenance and reliever}

Periodic fluctuations in symptoms and airway inflammation are characteristic of asthma and treatment requirements can vary over time. Reliever medications such as short-acting $\beta_{2}$-agonist provide rapid bronchodilation and symptom relief but do not treat the underlying inflammatory process. O'Byrne and colleagues challenged the treatment paradigm of fixed dosing of ICS/LABA and proposed that combination therapy could be used as both maintenance and reliever therapy. ${ }^{79}$ In this pivotal study, the use of the combination of a rapid LABA (formoterol) and an inhaled glucocorticosteroid (budesonide) in a single inhaler both as a controller and reliever was effective in maintaining high levels of asthma control. This was 
a double-blind, parallel-group study where 2,760 patients aged 4 to 80 years were randomized to receive either: 1) budesonide/formoterol $80 / 4.5 \mu \mathrm{g}$ bid as maintenance therapy plus budesonide/formoterol $80 / 4.5 \mu \mathrm{g}$ as needed for reliever therapy, 2) budesonide/formoterol $80 / 4.5 \mu \mathrm{g}$ bid as maintenance plus terbutaline $0.4 \mathrm{mg}$ as reliever, or 3) budesonide $320 \mu \mathrm{g}$ bid as maintenance plus terbutaline $0.4 \mathrm{mg}$ as reliever. The patients who took budesonide/ formoterol as both maintenance and reliever therapy had a reduced risk of severe asthma exacerbations, need for systemic steroids, improved asthma symptoms and improved lung function compared with the traditional fixed-dosing regimens. More importantly, the average daily dose of ICS received per patient was lower in the budesonide/formoterol groups and all of the medications were well tolerated.

Rabe and colleagues demonstrated that the combination budesonide/formoterol used for both maintenance and reliever improved asthma control with a lower steroid dose compared with higher doses of budesonide. ${ }^{80} 697$ patients aged 12 years and older were randomized to receive either budesonide/formoterol $80 / 4.5 \mu \mathrm{g}$ bid as maintenance therapy plus budesonide/formoterol $80 / 4.5 \mu \mathrm{g}$ as needed for reliever therapy or budesonide $160 \mu \mathrm{g}$ bid as maintenance therapy plus terbutaline $0.4 \mathrm{mg}$ as needed for reliever therapy. Patients receiving the budesonide/formoterol combination for both maintenance and relief had greater lung function, decreased risk of exacerbations, fewer hospitalizations, and decreased asthma symptoms. The increased efficacy of budesonide/formoterol was achieved with less ICS than was used in the budesonide group (mean dose, $240 \mu \mathrm{g}$ /day versus $498 \mu \mathrm{g} /$ day) and with $77 \%$ fewer oral steroid treatment days versus budesonide alone (114 days versus 498 days, respectively).

In the Symbicort Maintenance and Reliever Therapy (SMART) trial, the combination therapy with budesonide and formoterol used both as maintenance and rescue was shown to be an effective and well tolerated treatment approach for pediatric asthma management. ${ }^{81}$ This was a prospective study involving 41 centers in 12 countries. 341 children aged 4-11 years with uncontrolled asthma on current ICS therapy were randomized to receive either fixed-dose budesonide, fixed-dose combination budesonide/ formoterol or budesonide/formoterol maintenance and as needed therapy (SMART group). Children receiving the SMART regimen had reduced asthma exacerbations, reduced nocturnal symptoms, and improved lung function. $14 \%$ of patients receiving the SMART regimen had an exacerbation, compared to $38 \%$ and $26 \%$ of patients in the fixed-dose combination and fixed-dose budesonide groups, respectively. Time to first exacerbation was significantly longer in the SMART group compared to fixed-dose combination and fixed-dose budesonide groups, respectively. This benefit was attained while using less than half the daily dose of budesonide compared with the fixed-dose budesonide group. In addition, yearly growth was higher by $1 \mathrm{~cm}$ for children in the budesonide/formoterol group versus those on higher fixed-dose daily budesonide. This approach to asthma management is currently not guideline based therapy but may provide a better alternative to improving control and decreasing risk. The benefit in preventing exacerbations and improving asthma control appears to be a consequence of early intervention and providing additional anti-inflammatory therapy and rapid symptom relief. The timing of the increased steroid dose in close proximity to asthma worsening may be the key to the effectiveness of this strategy, although other studies have shown that increasing the ICS dosing during an acute attack may not reduce risk of asthma related morbidity. ${ }^{82-84}$

The unique pharmacological properties of budesonide/ formoterol in a single inhaler make it suitable for both maintenance dosing and as reliever therapy. Whether this approach can be employed with other combinations of controller and reliever requires further study. Currently, the budesonide/formoterol single combination inhaler is not licensed by the US FDA for use as reliever therapy for the treatment of asthma. However, the 2006 GINA guidelines do recommend that if a combination inhaler containing formoterol and budesonide is selected, it may be used for both rescue and maintenance therapy. ${ }^{2}$

Finally, adherence to therapy is an important factor in the success of asthma treatment. Patients often link their poor adherence to prescribed ICS therapy to the lack of an immediate effect, unlike the rapid onset of effect experienced with short-acting $\beta_{2}$-agonist. ${ }^{85}$ Budesonide/formoterol maintenance and rescue therapy may provide a significant benefit for patients for whom adherence to two separate drugs may present serious difficulties or confusion.

\section{Summary}

Current asthma guidelines recommend treatment of asthma in children towards achieving and maintaining asthma control in order to reduce impairment due to asthma symptoms and to reduce risk of future asthma exacerbations. This approach likely reduces morbidity and mortality associated with uncontrolled asthma. Newer combination agents such as budesonide and fomoterol have been shown to be safe and 
effective in treatment of asthma in children. Use of long-term controller agents like this in combination with improved compliance and treatment of co-morbid conditions have been successful in this endeavor. Early studies even suggest that this combination can be used to reduce asthma exacerbations when used on a more intermittent basis in some patients. However, more studies have to be completed before this strategy can be universally recommended.

\section{Disclosures}

The authors report no conflicts of interest in this work. Dr. Kwong has been a Speaker for Sepracor, Genentech, and Novartis, and has received a research grant from Merck.

\section{References}

1. National Asthma Education and Prevention Program. Guidelines for the Diagnosis and Management of Asthma: Expert Panel Report 3. Bethesda, MD: National Institutes of Health, National Heart, Lung and Blood Institute; 2007.

2. Masoli M, Fabian D, Holt S, Beasley R; Global Initiative for Asthma (GINA) Program. Global Initiative for Asthma (GINA) program: the global burden of asthma: executive summary of the GINA Dissemination Committee report. Allergy. 2004;59(5):469-478.

3. Siersted HC, Boldsen J, Hansen HS, Mostgaard G, Hyldebrandt N. Population based study of risk factors for underdiagnosis of asthma in adolescence: Odense schoolchild study. BMJ. 1998;316(7132): 651-655; discussion, 655-656.

4. Speight AN, Lee DA, Hey EN. Underdiagnosis and undertreatment of asthma in childhood. Br Med J (Clin Res Ed). 1983;286(6373): 1253-1256.

5. Nichols B, Scott L, Jones S, Kwong KY, Morphew T, Jones CA. Detection of undiagnosed and poorly controlled asthma in a hospital-based outpatient pediatric primary care clinic using a health risk assessment system. J Asthma. 2009;46(5):498-505.

6. American Thoracic Society. Standardization of spirometry, 1994 update. Am J Respir Crit Care Med. 1995;152(3):1107-1136.

7. American Thoracic Society and European Respiratory Task Force. Standardization of lung function testing. Eur Respir J. 2005;26:948-968

8. Tager IB, Hanrahan JP, Tosteson TD, et al. Lung function, pre- and post-natal smoke exposure, and wheezing in the first year of life. Am Rev Respir Dis. 1993;147(4):811-817.

9. Miranda C, Busacker A, Balzar S, Trudeau J, Wenzel SE. Distinguishing severe asthma phenotypes: role of age at onset and eosinophillic inflammation. J Allergy Clin Immunol. 2004;113(1):101-108.

10. Bel EH. Clinical phenotypes of asthma. Curr Opin Pulm Med. 2004;10(1):44-50

11. Kelley CF, Mannino DM, Homa DM, Savage-Brown A, Holguin F. Asthma phenotypes, risk factors, and measures of severity in a national sample of US children. Pediatrics. 2005;115(3):726-731.

12. Castro-Rodriguez JA, Holberg CJ, Wright AL, Martinez FD. A clinical index to define risk of asthma in young children with recurrent wheezing. Am J Respir Crit Care Med. 2000;162(4 Pt 1): 1403-1406.

13. Bateman ED, Boushey HA, Bousquet J, et al; GOAL Investigators Group. Can guideline-defined asthma control be achieved? The Gaining Optimal Asthma ControL study. Am J Respir Crit Care Med. 2004;170(8):836-844.

14. Kwong KY, Morphew T, Scott L, Guterman J, Jones CA. Asthma control and future asthma-related morbidity in inner-city asthmatic children. Ann Allergy Asthma Immunol. 2008;101(2):144-152.
15. Scott L, Nichols B, Choi Kwong KY, Morphew T, Jones CA Longitudinal patterns of predominant asthma disease activity in pediatric patients enrolled in an asthma-specific disease management program. J Asthma. 2008;45(6):501-505.

16. Calhoun WJ, Sutton LB, Emmett A, Dorinsky PM. Asthma variability in patients previously treated with beta2-agonists alone. J Allergy Clin Immunol. 2003;112(6):1088-1094.

17. Sears MR. Epidemiology of asthma exacerbations. J Allergy Clin Immunol. 2008;122(4):662-668.

18. Tan WC. Viruses in asthma exacerbations. Curr Opin Pulm Med. 2005;11(1):21-26.

19. Jones CA, Clement LT, Morphew T, et al. Achieving and maintaining asthma control in an urban pediatric disease management program: the Breathmobile Program. J Allergy Clin Immunol. 2007;119(6):1445-1453.

20. Howell G. Nonadherence to medical therapy in asthma: risk factors, barriers, and strategies for improving. J Asthma. 2008;45(9):723-729.

21. Haughney J, Price D, Kaplan A, et al. Achieving asthma control in practice: understanding the reasons for poor control. Respir Med. 2008;102(12):1681-1693.

22. Burgess SW, Sly PD, Morawska A, Devadason SG. Assessing adherence and factors associated with adherence in young children with asthma. Respirology. 2008;13(4):559-563.

23. Braunstahl GJ, Overbeek SE, Kleinjan A, Prins JB, Hoogsteden HC, Fokkens WJ. Nasal allergen provocation induces adhesion molecule expression and tissue eosinophilia in upper and lower airways. J Allergy Clin Immunol. 2001;107(3):469-476.

24. Braunstahl GJ, Hellings PW. Nasobronchial interaction mechanisms in allergic airway airways disease. Curr Opin Otolaryngol Head Neck Surg. 2006;14(3):176-182.

25. Adams RJ, Fuhlbrigge AL, Finkelstein JA, Weiss ST. Intranasal steroids and the risk of emergency department visits for asthma. J Allergy Clin Immunol. 2002;109(4):636-642.

26. Corren J, Manning BE, Thompson SF, Hennessy S, Strom BL. Rhinitis therapy and the prevention of hospital care for asthma: a case-control study. J Allergy Clin Immunol. 2004;113(3):415-419.

27. Crystal-Peters J, Neslusan C, Crown WH, Torres A. Treating allergic rhinitis in patients with comorbid asthma; the risk of asthma-related hospitalizations and emergency department visits. $J$ Allergy Clin Immunol. 2002;109(1):57-62

28. Kiljander TO, Salomaa ER, Hietanen EK, Terho EO. Gastroesophageal reflux in asthmatics; a double-blind, placebo-controlled crossover study with omeprazole. Chest. 1999;116(5):1257-1264.

29. Littner MR, Leung FW, Ballard ED 2nd, Huang B, Samra NK; Lansoprazole Asthma Study Group. Effects of 24 weeks of lansoprazole therapy on asthma symptoms exacerbations, quality of life, and pulmonary function in adult asthmatic patients with acid reflux symptoms. Chest. 2005;128(3):1128-1135.

30. Booth H, Richmond I, Ward C, Gardiner PV, Harkawat R, Walters EH. Effect of high dose inhaled fluticasone propionate on airway inflammation in asthma. Am J Respir Crit Care Med. 1995;152(1):45-52.

31. Busse WW. What role for inhaled steroids in chronic asthma? Chest. 1993;104(5):1565-1571.

32. Duddridge M, Ward C, Hendrick DJ, Walters EH. Changes in bronchoalveolar lavage inflammatory cells in asthmatic patients treated with high dose inhaled beclomethasone dipropionate. Eur Respir J. 1993;6(4):489-497.

33. Juniper EF, Kline PA, Vanzieleghem MA, Ramsdale EH, O’Byrne PM, Hargreave FE. Effect of long-term treatment with an inhaled corticosteroid (budesonide) on airway hyper-responsiveness and clinical asthma in nonsteroid-dependent asthmatics. Am Rev Respir Dis. 1990;142(4):832-836.

34. Barnes PJ, Pederson S. Efficacy and safety of inhaled corticosteroids in asthma. Report of a workshop held in Eze, France, October 1992. Am Rev Respir Dis. 1993;148(4 Pt 2):S1-S26.

35. Suissa S, Ernst P, Benayoun S, Baltzan M, Cai B. Low-dose inhaled corticosteroids and the prevention of death from asthma. $N$ Engl J Med. 2000;343(5):332-336. 
36. Capewell S, Reynolds S, Shuttleworth D, Edwards C, Finlay AY. Purpura and dermal thinning associated with high dose inhaled corticosteroids. BMJ. 1990;300(6739):1548-1551.

37. Brown PH, Greening AP, Crompton, et al. Large volume spacer devices and the influence of high dose beclomethasone dipropionate on hypothalamo-pituitary-adrenal axis function. Thorax. 1993;48(3):233-238.

38. Lipworth BJ. Systemic adverse effects of inhaled corticosteroid therapy: A systematic review and meta-analysis. Arch Intern Med. 1999;159(9):941-955.

39. Pauwels RA, Yernault JC, Demedts MG, Geusens P. Safety and efficacy of fluticasone and beclomethasone in moderate to severe asthma. Belgian Multicenter Study Group. Am J Respir Crit Care Med. 1998;157(3 Pt 1):827-832.

40. Roux C, Kolta S, Desfougères JL, Minini P, Bidat E. Long-term safety of fluticasone propionate and nedocromil sodium on bone in children with asthma. Pediatrics. 2003;111(6 Pt 1)706-713.

41. The Childhood Asthma Management Program Research Group. Longterm effects of budesonide or nedocromil in children with asthma. NEng J Med. 2000;343(15):1054-1063.

42. Guilbert TW, Morgan WJ, Zeiger RS, et al. Long-term inhaled corticosteroids in preschool children at high risk for asthma. $N$ Engl J Med. 2006;354(19):1985-1997.

43. Leone FT, Fish JE, Szefler SJ, et al. Systemic review of the evidence regarding potential complications of inhaled corticosteroid use in asthma: collaboration of American College of Chest Physicians, American Academy of Allergy, Asthma, and Immunology, and American College of Allergy, Asthma, and Immunology. Chest. 2003;124(6):2329-2340.

44. Pauwels RA, Pederson S, Busse WW, et al. Early intervention with budesonide in mild persistent asthma: a randomized double-blind trial. Lancet. 2003;361(9363):1071-1076.

45. Brogden RN, McTavish D. Budesonide. An updated review of its pharmacological properties, and therapeutic efficacy in asthma and rhinitis. Drugs. 1992;44(3):375-407.

46. Shapiro G, Bronsky EA, LaForce CF, et al. Dose-related efficacy of budesonide administered via dry powder inhaler in the treatment of children with moderate to severe persistent asthma. J Pediatr. 1998;132(6):976-982.

47. The Childhood Asthma Management Program Research Group. Longterm effects of budesonide or nedocromil in children with asthma. NEng J Med. 2000;343(15):1054-1063.

48. Sheffer AL, Silverman M, Woolcock AJ, Díaz PV, Lindberg B, Lindmark B. Long-term safety of once-daily budesonide in patients with early-onset mild persistent asthma: Results of the Inhaled Steroid Treatment as Regular Therapy in Early Asthma (START) study. Ann Allergy Asthma Immunol. 2005;94(1):48-54.

49. Agertoft L, Pedersen S. Effect of long-term treatment with inhaled budesonide on adult height in children with asthma. $N$ Engl J Med. 2000;343(15):1064-1069.

50. Wolters OD. Impact of inhaled and intranasal corticosteroids on the growth of children. BioDrugs. 2000;13(5):347-357.

51. Inoue T, Doi S, Takamatsu I, Murayama N, Kameda M, Toyoshima K. Effect of long-term treatment with inhaled belcometasone dipropionate on growth of asthmatic children. J Asthma. 1999;36(2): $159-164$.

52. Gulliver T, Morton R, Eid N. Inhaled corticosteroids in children with asthma: pharmacologic determinants of safety and efficacy and other clinical considerations. Paediatr Drugs. 2007;9(3):185-194.

53. Pederson S. Clinical safety of inhaled corticosteroids for asthma in children: an update of long-term trials. Drug Saf. 2006;29(7):599-612.

54. Pauwels RA, Ofdahl CG, Postma DS, et al. Effect of inhaled formoterol and budesonide on exacerbations of asthma. $N$ Engl $J$ Med. 1997;337(20):1405-1411.

55. O’Byrne PM, Barnes PJ, Rodriguez-Roisin R, et al. Low dose inhaled budesonide and formoterol in mild persistent asthma. Am J Respir Crit Care Med. 2001;164(8 Pt 1):1392-1397.
56. Matz J, Emmett A, Rickard K, Kalberg C. Addition of salmeterol to low-dose fluticasone versus higher-dose fluticasone; an analysis of asthma exacerbations. J Allergy Clin Immunol. 2001;107(5): 783-789.

57. Ni CM, Greenstone IR, Ducharme FM. Addition of inhaled long-acting beta2-agonist to inhaled steroids as first line therapy for persistent asthma in steroid-naïve adults. Cochrane Database Syst Rev. 2005;2:CD005307.

58. Sin DD, Man J, Sharpe H, Gan WQ, Man SF. Pharmacological management to reduce exacerbations in adults with asthma: a systematic review and meta-analysis. JAMA. 2004;292(3):367-376.

59. Masoli M, Weatherall M, Holt S, Beasley R. Moderate dose inhaled corticosteroids plus salmeterol versus higher doses of inhaled corticosteroids in symptomatic asthma. Thorax. 2005;60(9):730-734.

60. Tal A, Simon G, Vermeulen JH, et al. Budesonide/formoterol in a single inhaler versus inhaled corticosteroids alone in the treatment of asthma. Pediatr Pulmonol. 2002;34(5):342-350.

61. Pohunek P, Kuna P, Jorup C, Boeck KD. Budesonide/formoterol improves lung function compared with budesonide alone in children with asthma. Pediatr Allergy Immunol. 2006;17(6):458-465.

62. van Noord JA, Smeets JJ, Raaijmakers JA, Bommer AM, Maesen FP. Salmeterol versus formoterol in patients with moderately severe asthma: onset and duration of action. Eur Respir J. 1996;9(8):1684-1688.

63. Palmqvist M, Persson G, Lazer L, Rosenborg J, Larsson P, Lötvall J. Inhaled dry-powder formoterol and salmeterol in asthmatic patients: onset of action, duration of effect and potency. Eur Respir J. 1997;10(11):2484-2489.

64. Ringdal N, Derom E, Wåhlin-Boll E, Pauwels R. Onset and duration of action of single doses of formoterol inhaled via Turbuhaler ${ }^{\mathbb{B}}$. Respir Med. 1998;92(8):1017-1021.

65. Seberová E, Andersson A. Oxis ${ }^{\circledR}$ (formoterol given by Turbuhaler ${ }^{\circledR}$ ) showed as rapid an onset of action as salbutamol given by a pMDI. Respir Med. 2000;94(6):607-611.

66. Nelson HS, Weiss ST, Bleecker ER, Yancey SW, Dorinsky PM; SMART Study Group. The salmeterol multicenter asthma research trial: a comparison of usual pharmacotherapy for asthma or usual pharmacotherapy plus salmeterol. Chest. 2006;129(1):15-26.

67. Mann M, Chowdhury B, Sullivan E, Nicklas R, Anthracite R, Meyer RJ. Serious asthma exacerbations in asthmatics treated with high-dose formoterol. Chest. 2003;124(1):70-74.

68. Israel E, Chinchilli VM, Ford JG, et al. Use of regularly scheduled albuterol treatment in asthma: genotype-stratified, randomised, placebo-controlled cross-over trial. Lancet. 2004;364(9444):1505-1512.

69. Wechsler ME, Lehman E, Lazarus SC, et al. Beta-adrenergic receptor polymorphisms and response to salmeterol. Am J Respir Crit Care Med. 2006;173(5):519-526.

70. Bisgaard $\mathrm{H}$. Effect of long-acting beta2 agonist on exacerbation rates of asthma in children. Pediatr Pulmonol. 2003;36(5):391-398.

71. Lazarus SC, Boushey HA, Fahy JV, et al; Asthma Clinical Research Network for the National Heart, Lung, and Blood Institute. Long-acting beta 2 agonist monotherapy vs continued therapy with inhaled corticosteroids in patients with persistent asthma: a randomized controlled trial. JAMA. 2001;285(20):2583-2593.

72. Bleecker ER, Postma DS, Lawrance RM, et al. Effect of ADRB2 polymorphisms on response to long-acting beta2-agonist therapy: a pharmacogenetic analysis of two randomised studies. Lancet. 2007;370:2118-2125.

73. Lofdahl CG, Reise TF, Leff JA, et al. Randomized, placebo controlled trial of effect of a leukotriene receptor antagonist, montelukast, on tapering inhaled corticosteroids in asthmatic patients. $B M J$. 1999;319(7202):87-90.

74. Price DB, Hernandez D, Magyar P, et al. Randomised controlled trial of montelukast plus inhaled budesonide versus double dose inhaled budesonide in adult patients with asthma. Thorax. 2003;58(3):211-216.

75. Lofdahl CG, Reise TF, Leff JA, et al. Randomized, placebo controlled trial of effect of a leukotriene receptor antagonist, montelukast, on tapering inhaled corticosteroids in asthmatic patients. BMJ. 1999;319(7202):87-90. 
76. Nelson HS, Busse WW, Kerwin E, et al. Fluticasone propionate/ salmeterol combination provides more effective asthma control than low-dose inhaled corticosteroid plus montelukast. J Allergy Clin Immunol. 2000;106(6):1088-1095.

77. Fish JE, Israel E, Murray JJ, et al. Salmeterol powder provides significantly better benefit than montelukast in asthmatic patients receiving concomitant inhaled corticosteroid therapy. Chest. 2001;120(2):423-430.

78. Ringdal N, Eliraz A, Pruzinec R, et al. The salmeterol/fluticasone combination is more effective than fluticasone plus oral montelukast in asthma. Respir Med. 2003;97(3):234-241.

79. O'Byrne PM, Bisgaard H, Godard PP, et al. Budesonide/formoterol combination therapy as both maintenance and reliever medication in asthma. Am J Respir Crit Care Med. 2005;171(2):129-136.

80. Rabe KF, Pizzichini E, Stallberg B, et al. Budesonide/formoterol in a single inhaler for maintenance and relief in mild-to-moderate asthma: a randomized, double-blind trial. Chest. 2006;129(2):246-256.
81. Bisgaard H, Le Roux P, Bjåmer D, Dymek A, Vermeulen JH, Hultquist C. Budesonide/formoterol maintenance plus reliever therapy: a new strategy in pediatric asthma. Chest. 2006;130(6):1733-1743.

82. Rice-McDonald G, Bowler S, Staines G, Mitchell C. Doubling daily inhaled corticosteroid dose is ineffective in mild to moderately severe attacks of asthma in adults. Intern Med J. 2005;35(12):693-698.

83. FitzGerald JM, Becker A, Sears MR, Mink S, Chung K, Lee J; Canadian Asthma Exacerbation Study Group. Doubling the dose of budesonide versus maintenance treatment in asthma exacerbations. Thorax. 2004;59(7):550-556.

84. Garrett J, Williams S, Wong C, Holdaway D. Treatment of acute asthmatic exacerbations with an increased dose of inhaled steroid. Arch Dis Child. 1998;79(1):12-17.

85. Jónasson G, Carlsen KH, Sødal A, Jonasson C, Mowinckel P. Patient compliance in a clinical trial with inhaled budesonide in children with mild asthma. Eur Respir J. 1999;14(1):150-154.
Therapeutics and Clinical Risk Management

\section{Publish your work in this journal}

Therapeutics and Clinical Risk Management is an international, peerreviewed journal of clinical therapeutics and risk management, focusing on concise rapid reporting of clinical studies in all therapeutic areas, outcomes, safety, and programs for the effective, safe, and sustained use of medicines. This journal is indexed on PubMed Central, CAS,

\section{Dovepress}

EMBase, Scopus and the Elsevier Bibliographic databases. The manuscript management system is completely online and includes a very quick and fair peer-review system, which is all easy to use. Visit http://www.dovepress.com/testimonials.php to read real quotes from published authors.

Submit your manuscript here: http://www.dovepress.com/therapeutics-and-clinical-risk-management-journal 